\title{
F-Shape Dual-Band MIMO Antenna System for Next- Generation Smartphone Applications
}

\author{
Atta Ullah ${ }^{1}$, Naser Ojaroudi Parchin ${ }^{2}$, Waqas Manan ${ }^{3}$, Yasir I. A. Al-Yasir' ${ }^{4}$, Raed A. Abd- \\ Alhameed ${ }^{5,6}$ \\ \{A.Ullah5@Bradford.ac.uk ${ }^{1}$, N.OjaroudiParchin@Bradford.ac.uk ${ }^{2}$, \\ $\left.\underline{\text { R.A.A.Abd@Bradford.ac.uk }}{ }^{5,6}\right\}$
}

Faculty of Engineering and Informatics, University of Bradford, Bradford BD7 1DP, UK $1,2,3,4,5$ Information and Communication Engineering Department, Basrah University College of Science and Technology, Iraq $^{6}$

\begin{abstract}
This work presents a 6-element dual-band multiple-input multiple-output (MIMO) antenna in an F-shape for smartphone mobile communication.. It has six antenna elements covering dual-frequency bands that cover the sub- $6 \mathrm{GHz}$ spectrum at $3.42-3.77 \mathrm{GHz}$ and the sub-6 GHz spectrum at $5.30-5.63 \mathrm{GHz}$. The fundamentals are served by F-shaped microstrip feeding positions while the ground is cut in L shape with every antenna element. The proposed scheme's essential elements are examined. It is concerned with respectable S-parameters, adequate isolation, adequate radiation analysis, and efficiency. As proposed by the double-band frequency of 5G smartphones, Ant 3 has a maximum return loss of $-35 \mathrm{~dB}$ at $3.6 \mathrm{GHz}$ and Ant 5 and Ant 6 have a maximum return loss of $-38 \mathrm{~dB}$ at $5.4 \mathrm{GHz}$.
\end{abstract}

Keywords: 5G communication, dual-band antenna, smartphone compacted antenna array.

\section{Introduction}

Following the release of the $5 \mathrm{G}$ New Radio (NR) in June 2018, fifth-generation (5G) telecommunications technology is once again anticipating exponential growth, necessitating the development of a 5G antenna design [1-2]. As mobile and communication technology becomes more widely adopted, the use of wireless technology and its applications has grown at a rapid pace. Artificial intelligence (AI), the internet of things (IoT), and mobile video streaming have all contributed to this significant advancement in wireless communication [34]. Fifth-generation mobile networks (or 5G) offer the latest solution for advancing wireless communication technology and achieving the mounting need for cell phone communictaions throughout the subsequent phase pending $6 \mathrm{G}$ arrives [5-8]. 5G is the definitive answer for wireless communication technology to achieve improved data rates and low latency [9-10]. Presently, the 5th generation of cellular phone communication of the band is recognized as dual regularity bands in $3.42-3.77 \mathrm{GHz}$ and $5.30-5.63 \mathrm{GHz}$. The aggregate of $700 \mathrm{MHz}$ bandwidth can be achieved1[11-13]. Then in communication structures, multiple-input multiple-output (MIMO) practises can substantially enhance series operation and channel capability without increasing transmit power and increasing extra transmission bandwidth. 
Nevertheless, as the reduction and probability of wireless gadgets turn out to be the typical mainstream, the accessible spaces for the antenna are further inadequate [14-16]. Hence, it is extremely crucial to project an efficient MIMO antenna. To adopt the frequently utilized wireless machines, publishing MIMO antenna is additional alternatives. Though, there is powerful mutual coupling when the space amongst MIMO antenna components is very close together. It is perverse to the aspiration for sharper isolation and lowers envelop correlation coefficients. Therefore, it is crucial to diminish the mutual coupling among the antenna components [17-18].

However, as the shrinking and compactness of developed wireless systems mainstream, the obtainable planetary for antennas is more restricted. Consequently, it is very compulsory to project a compressed MIMO antenna. To adapt to the usually used wireless systems, printing MIMO antennas is a basic choice [19]. However, there is solid mutual coupling when the detachment between MIMO antenna basics is very adjacent. It is conflicting to the aspiration for higher isolation and lower envelope correlation coefficients. It is crucial to decrease the mutual coupling among the antenna fundamentals [20].

$5.30-5.63 \mathrm{GHz}$ is accessible in the suggested architecture to facilitate Sub $6 \mathrm{GHz} 5 \mathrm{G}$ mobile communications. The modernization of the decoupling proposal proposed in this editorial not only efficiently increases separations, but also creates a new booming theme in an alternative frequency band, which covers $5.30-5.63 \mathrm{GHz}$ to achieve dual-band working performance, allowing space use in mobile devices to be efficiently developed [21-23]. It describes the Sparameter, maximum gain, user effects, radiation, and efficiency results of the given MIMO compact antenna array.

\section{Design and Configuration}

With the aid of CST Microwave Studio electromagnetic simulation software an F-shaped 6 Fatal antenna array is designed for this compact mobile MIMO system [24]. FR4 was used with a dielectric loss $\delta=0.019$ and $\varepsilon_{\mathrm{r}}=4.3$ in the proposed project. The dimension of the central substrate is $140 \times 70 \mathrm{~mm}^{2}$ shown in Figs. 1 and 2 show the Front Side and BackSide respectively. Table 1 demonstrate the comprehensive scopes of the antenna parameters. 


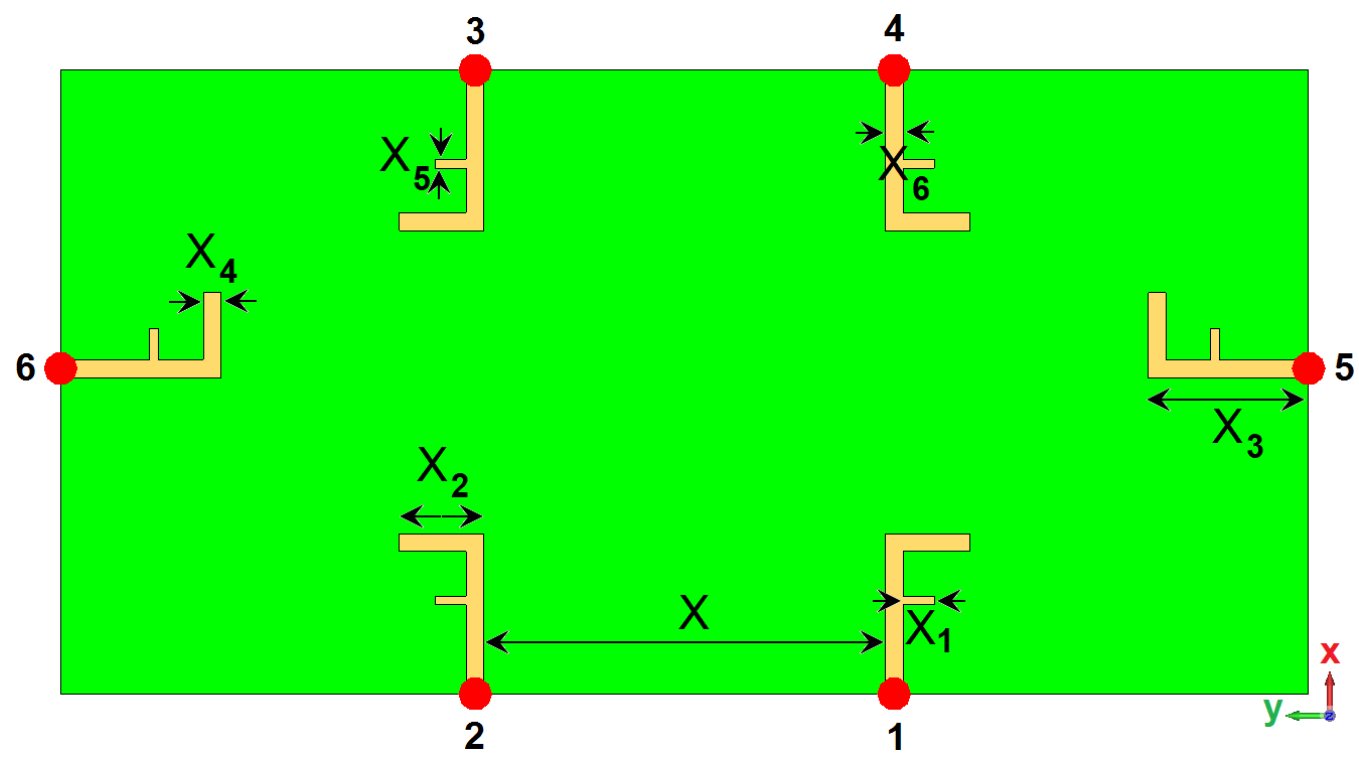

Fig 1. Front View of Schematic structure of the planned MIMO smartphone antenna.

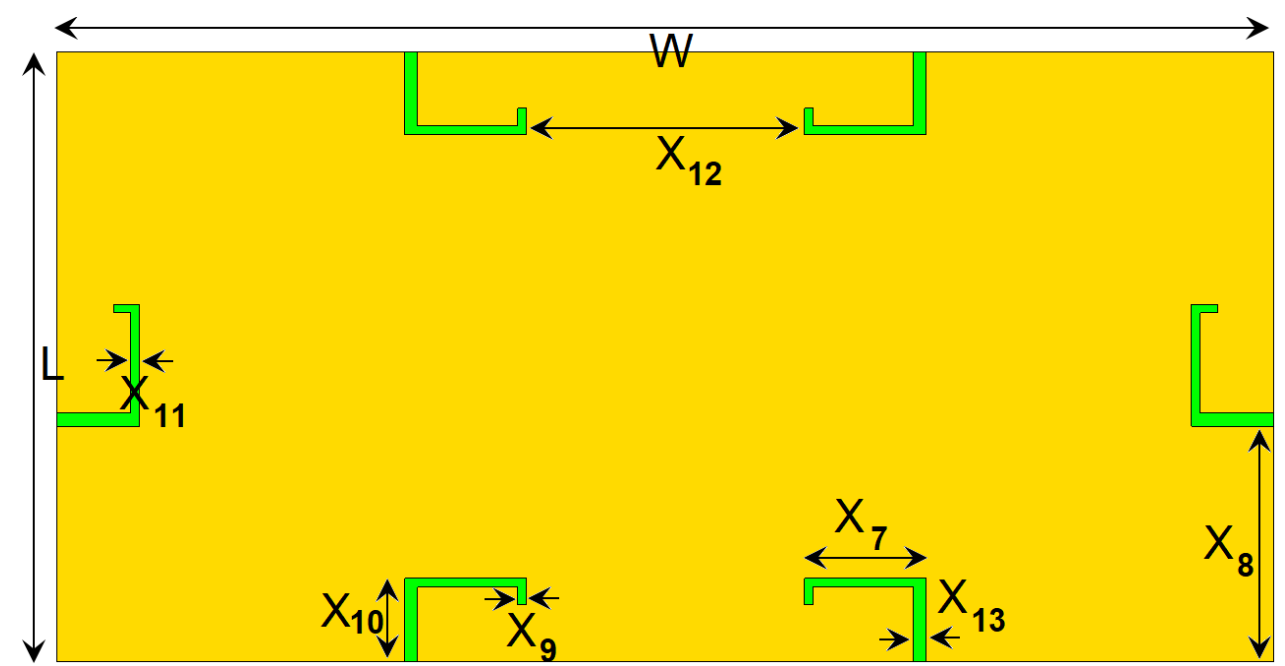

Figure 2. Bottom View of Schematic arrangement of the planned handset.

Table 1. Concluding magnitudes of the antenna parameters.

\begin{tabular}{cccccccccc}
\hline & $\mathbf{W}$ & $\mathbf{L}$ & $\mathbf{h}_{\text {sub }}$ & $\mathbf{X}$ & $\mathbf{X}_{\mathbf{1}}$ & $\mathbf{X}_{\mathbf{2}}$ & $\mathbf{X}_{\mathbf{3}}$ & $\mathbf{X}_{\mathbf{4}}$ & $\mathbf{X}_{\mathbf{5}}$ \\
\hline Value $(\mathrm{mm})$ & 140 & 70 & 0.8 & 48 & 4 & 8 & 18 & 2 & 1 \\
Parameter & $\mathbf{X}_{\mathbf{6}}$ & $\mathbf{X}_{\mathbf{7}}$ & $\mathbf{X}_{\mathbf{8}}$ & $\mathbf{X} \mathbf{9}$ & $\mathbf{X}_{\mathbf{1 0}}$ & $\mathbf{X}_{\mathbf{1 1}}$ & $\mathbf{X}_{\mathbf{1 2}}$ & $\mathbf{X}_{\mathbf{1 3}}$ & \\
Value $(\mathrm{mm})$ & 2 & 11.5 & 41.5 & 1 & 9.5 & 1 & 32 & 1.5 & \\
\hline
\end{tabular}




\section{Results and Discussions}

Figure. The characteristics and performance of the suggested six-element MIMO antenna arrays are analysed using CST software in this proposed study [28]. The antenna was developed to achieve the specified divergence return loss, radiation pattern, resonance frequency, and gain, and it uses a 50-ohm SMA connector to produce the required Sparameters. All of these limitations are explained in this article.

In order to support Sub $6 \mathrm{GHz}$ of $5 \mathrm{G}$ mobile communications, a 6-fundamentals MIMO array offers dual-band radio frequencies from 3.42 to $3.77 \mathrm{GHz}$ and from 5.30 to $5.63 \mathrm{GHz}$. Figure 3 shows the planned antenna's Snn. The proposed antenna's Smn (m not equal $\mathrm{n}$ ) is shown in Figure 3. The computer-generated S55 and S66 are both less than -20dB at 3.6 GHz, whereas the simulated S11, S22, S33, and S55 are all less than -20dB at $5.45 \mathrm{GHz}$. However, at $3.6 \mathrm{GHz}$, the Snn results for antenna fundamentals 1, 2, 3, and 4 are less than $-35 \mathrm{~dB}$, whereas the Snn results for antenna fundamentals 5 and 6 are greater than $-35 \mathrm{~dB}$. The results are less than $-40 \mathrm{~dB}$. The frequency is $5.45 \mathrm{GHz}$. This is primarily owing to the antenna basics' positioning [29-33]. At dual working bands, the antenna fundamentals show good mutual coupling results better than $-15 \mathrm{~dB}$ and $-12 \mathrm{~dB}$, as shown in Fig. 4.

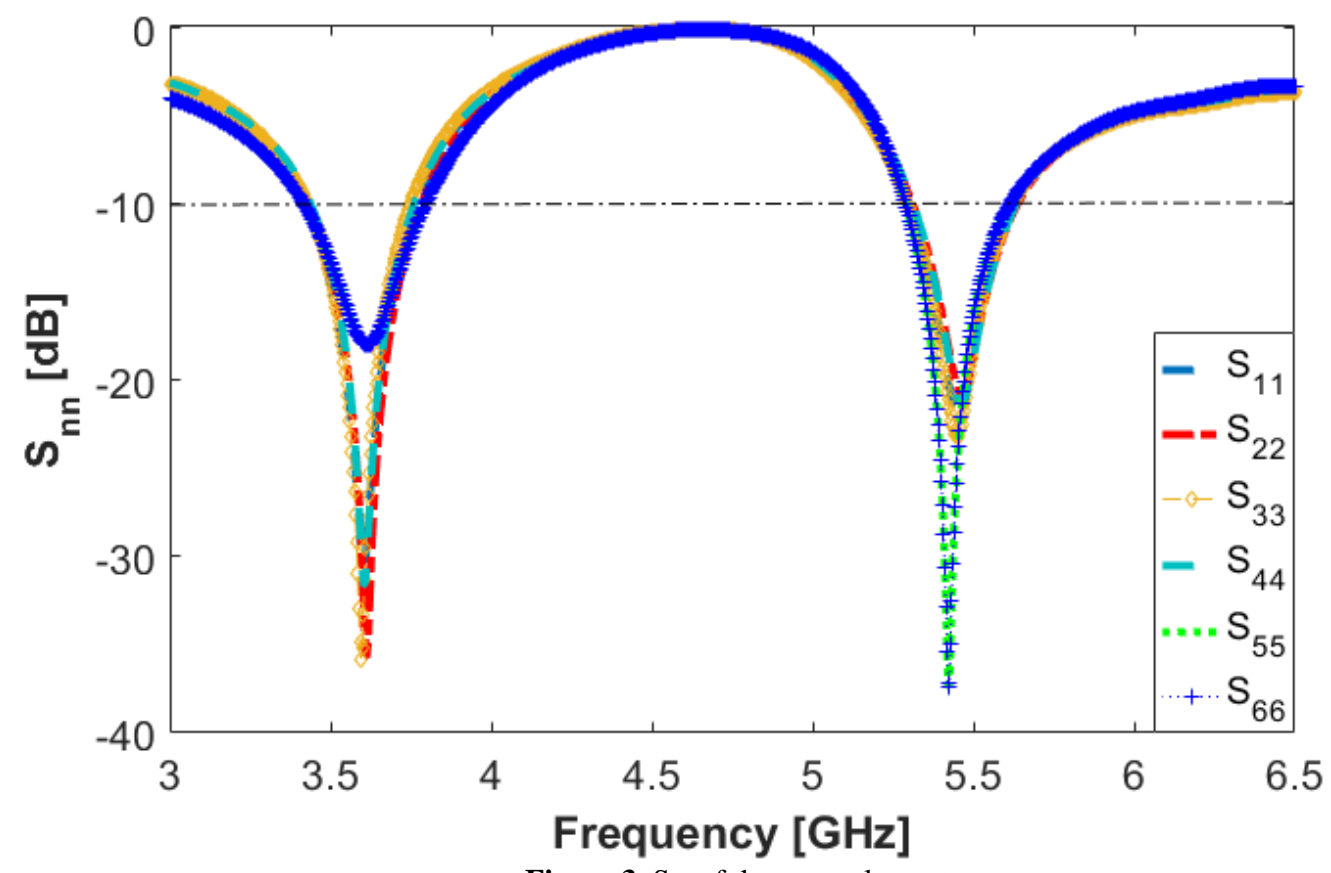

Figure 3. $S_{\mathrm{nn}}$ of the array elements. 

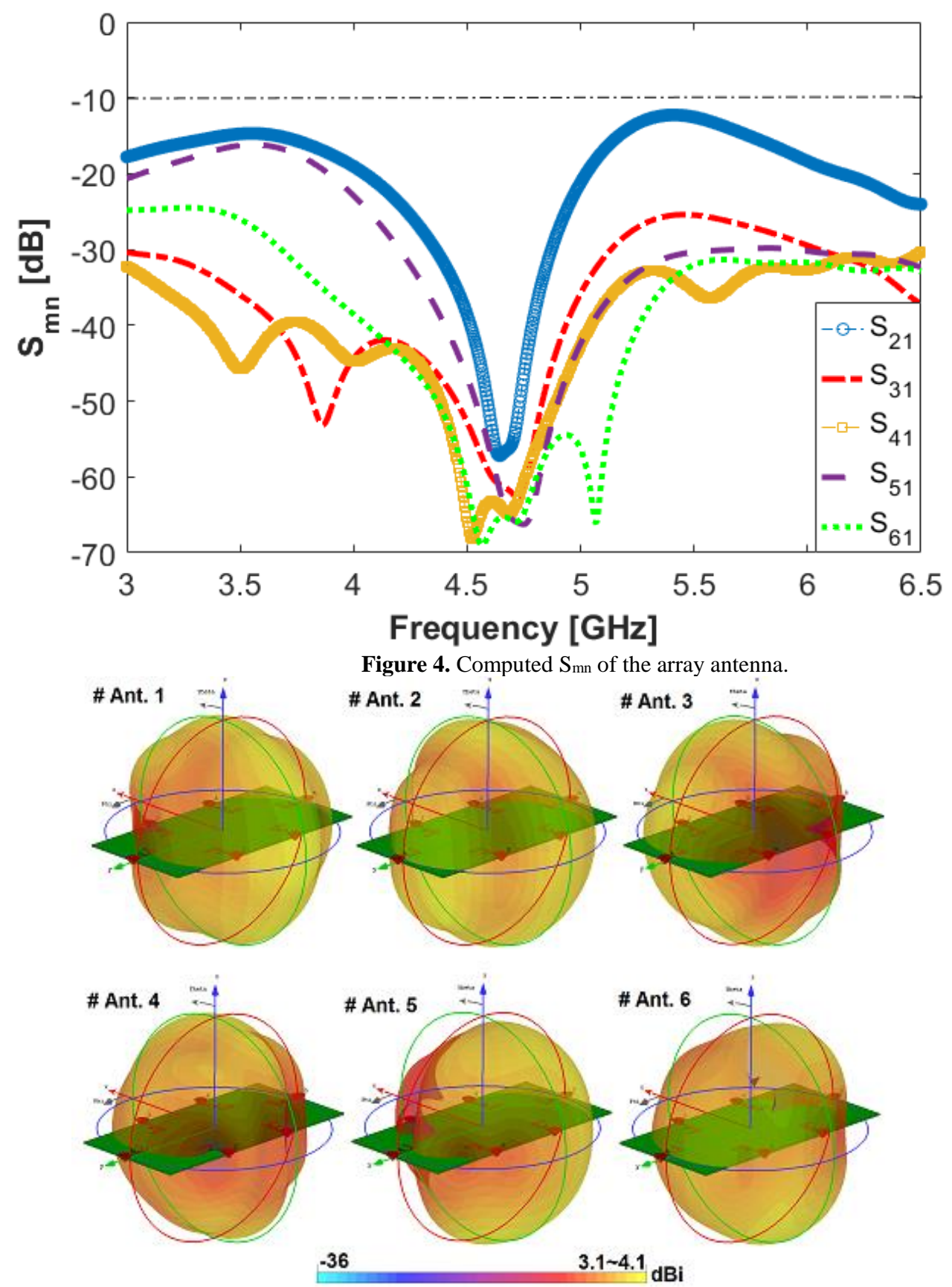

Figure 5. 3D antenna patterns at $3.6 \mathrm{GHz}$.

Figures 5 and 6 show the 3-D radiation patterns for the six fundamental components of the primary design at both frequencies. This approved 6-part MIMO antenna is capable of providing sufficient radiation analysis for individual radiators [34-37]. Based on the illustrated results, this varies from $3.1-3.11 \mathrm{~dB}$. However, at $5.45 \mathrm{GHz}$, the fundamentals exhibit a constant gain of $5.8 \mathrm{~dB}$. 

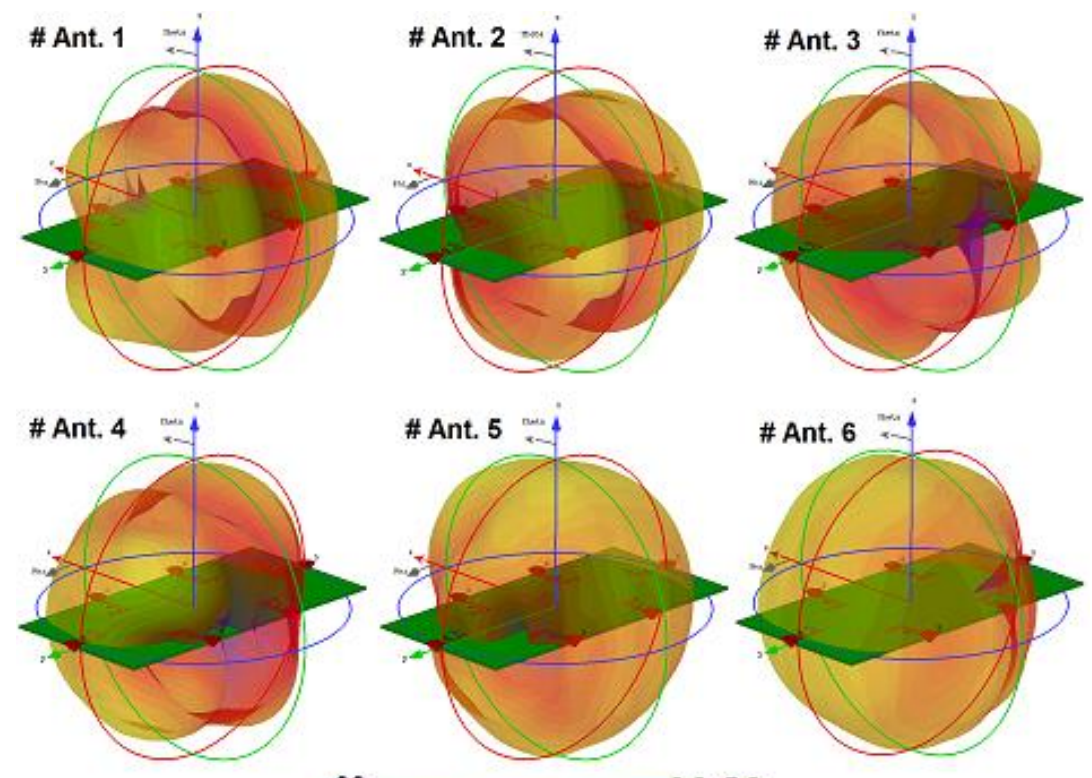

$-36$ $3.8-5.8 \mathrm{dBi}$

Figure 6. 3D radiation patterns at $5.45 \mathrm{GHz}$.

In Figures 7 and 8, we also show the antenna efficiencies. Inside the operating bands, extraordinary efficiencies with minor variations can be attained [38-44]. Figure. At the primary and additional working bands, radiation efficiencies exceed 95\% and 90\%, respectively, for the fundamentals of the proposed MIMO project. Furthermore, as shown in Figure 8, the antenna principles provide overall efficiencies of between 75 and 80 percent.

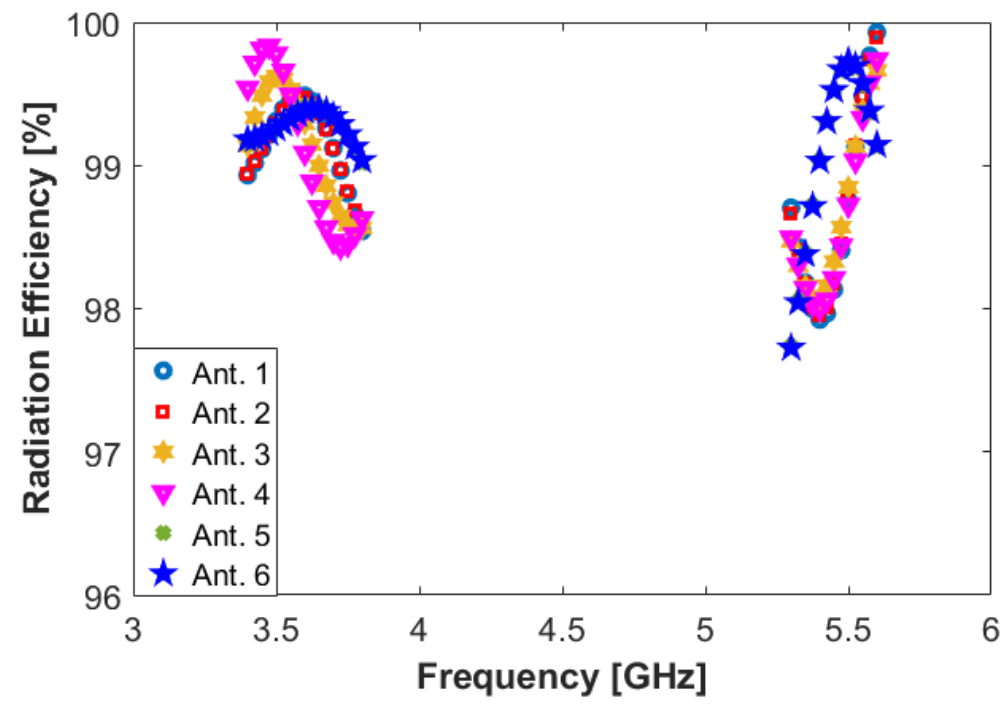

Figure 7. Variations of radiation efficiency versus frequency. 


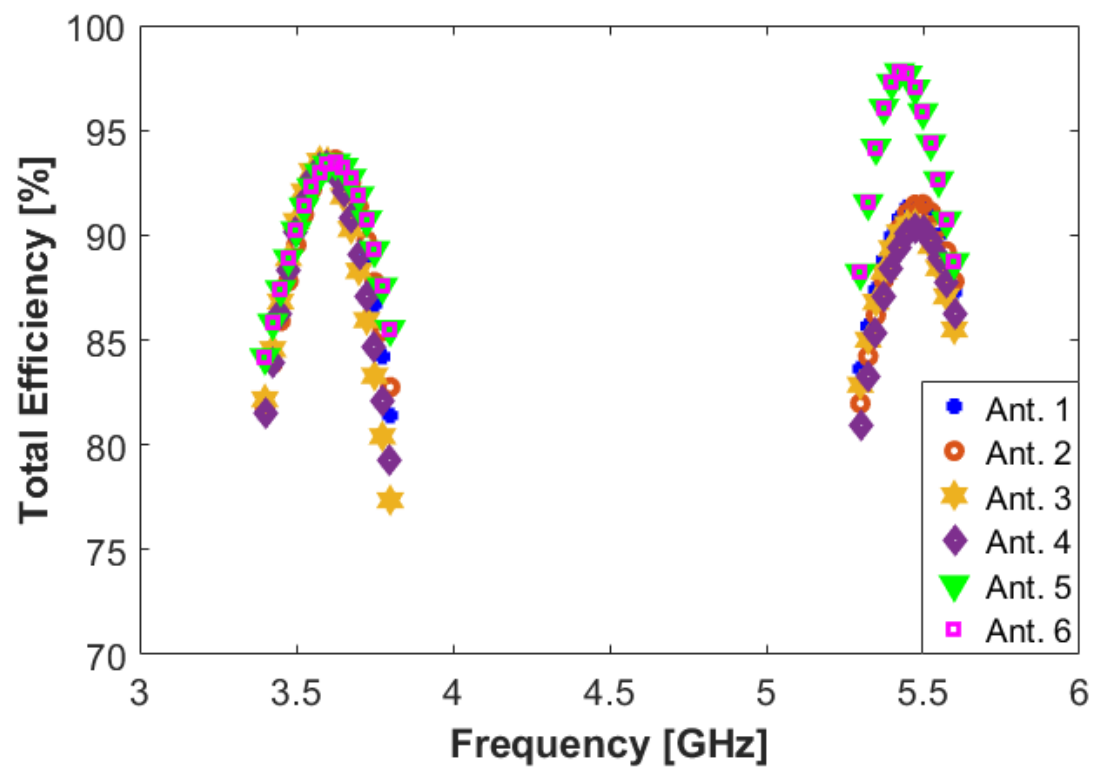

Figure 8. Variations of total efficiency against frequency.

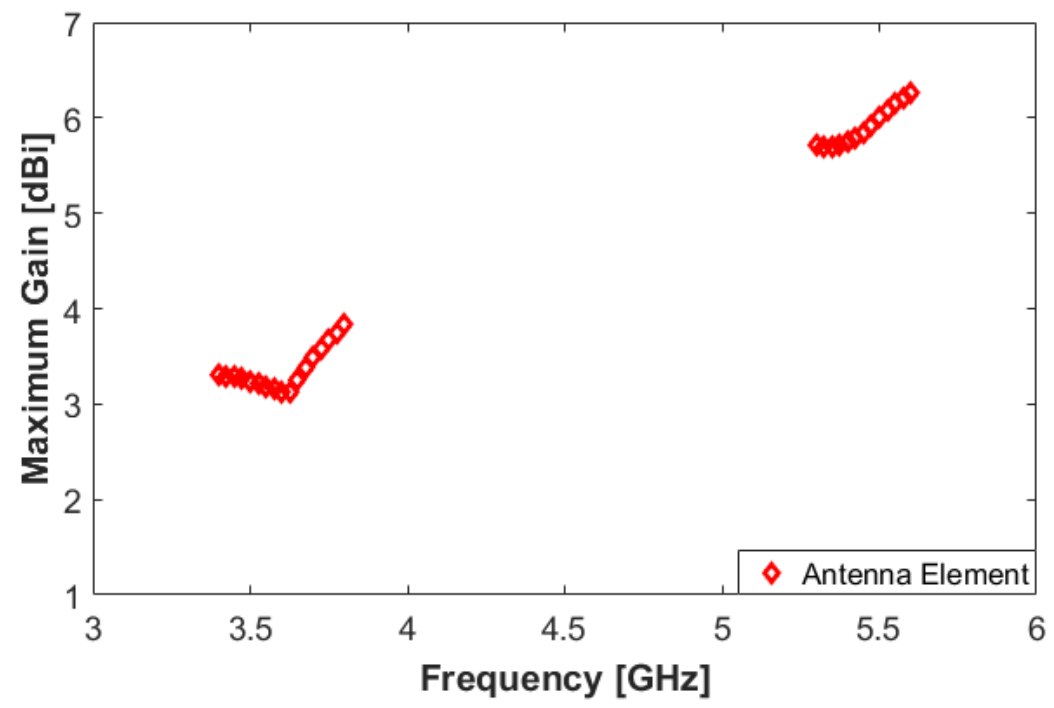

Figure 9. Power gain distribution.

At various frequencies, all antenna essentials display superior gains of greater than $3 \mathrm{dBi}$ up to $6.5 \mathrm{dBi}$. As can be seen, unlike the first operation band with a centre frequency of $3.6 \mathrm{GHz}$, the antenna's maximum gains at the second resonance are nearly constant at $6 \mathrm{dBi}$. 


\section{Conclusion}

An F-shape double-band 6-port 5G MIMO handset has been presented in this article. By exploiting some of the copper's radiation properties, the antenne array should suitably operate in a metal-framed smartphone. It is confirmed that $3.42-3.77 \mathrm{GHz}$ and $5.30-5.63 \mathrm{GHz}$ covered the required bandwidth. The antenna achieved $80 \%$ and $90 \%$ radiation and total efficiencies. Aveged over the bandwisth. 


\section{References}

[1] Lun Cui ,N et al: “ An 8-Element Dual-Band MIMO Antenna with Decoupling Stub for 5G Smartphone Applications" IEEE ANTENNAS AND WIRELESS PROPAGATION LETTERS, VOL. 18, NO. 10, OCTOBER 2019.

[2] 3GPP, "Rel-15 success spans 3GPP groups," 2018. [Online]. Avaliable: http://www.3gpp.org/news-events/3gpp-news/1965-rel-15_news

[3] Parchin, N. O. et al.: Microwave/RF components for 5G front-end systems, Avid Science (2019)

[4] Atta Ullah, N. et al: "Dual-Band MIMO Antenna System for Next Generation Smartphone Applications" 2020 IMDC-SDSP 8-10 April 2020, Antalya- Turkey

[5] Agiwal, M. Roy, A. and Saxena, N.: Next generation 5G wireless networks: A comprehensive survey. IEEE Commun. Surveys Tuts. Vol. 18, pp. 1617-1655 (2016)

[6] Ullah. A, N. Et al: "A Modified Design of Phased Array Antenna for UWB-5G Cellular Communications" 2020 IMDC-SDSP 8-10 April 2020, Antalya- Turkey

[7] Li, S. Q.: 5G: Intelligent mobile communication 1.0.ZTE Technol. Vol.5, pp. 47-48 (2016)

[8] Naser Ojaroudi Parchin, N. et al: Dual-Polarized Array Antenna with Quasi-End-Fire Radiation for 28 GHz 5G Mobile terminals" 2020 IMDC-SDSP 8-10 April Antalya- Turkey

[9] Ojaroudiparchin, N. et al.: Design of Vivaldi antenna array with end-fire beam steering function for 5G mobile terminals. TELFOR 2015, Belgrade, Serbia, pp. 587-590 (2015)

[10] Parchin, N. O. et al.: Eight-element dual-polarized MIMO slot antenna system for 5G smartphone applications. IEEE Access. Vol. 9, pp. 15612-15622 (2019)

[11] Andrews J. G. et al.: What will 5G be?," IEEE J. Sel. Areas Commun. Vol. 32, 1065-1082 (2014)

[12] Ojaroudi Parchin. N, et al: "Small-Clearance Phased Array Antenna Design with Miniaturized Elements for 5G Communications" 2020 IMDC-SDSP 8-10 April Antalya- Turkey.

[13] Jensen, M., Wallace, J.: A review of antennas and propagation for MIMO wireless communications. IEEE Trans. Antennas Propag. Vol. 52, pp. 2810-2824 (2004)

[14] Zhang, Z.: Antenna Design for Mobile Devices. Hoboken, NJ, USA: Wiley-IEEE Press (2011)

[15] Li, Y. et al.: High-isolation 3.5-GHz 8-antenna MIMO array using balanced open slot antenna element for 5G smartphones. IEEE Trans. Ant. Propag.(2019) doi:10.1109/TAP.2019.2902751.

[16] Parchin, N. O. et al.: Mobile-phone antenna array with diamond-ring slot elements for 5G massive MIMO systems. Electronics. Vol. 8, 521 (2019)

[17] Wang, L. et al.: Compact UWB MIMO antenna With high isolation using fence-type decoupling structure. IEEE Antennas and Wireless Propagation Letters. Vol. 8, pp. 1641-1645 (2019)

[18] Parchin, N. O. et al.: Dual-polarized MIMO antenna array design using miniaturized selfcomplementary structures for 5G smartphone applications. EuCAP Conference (2019)

[19] Mazloum, J. et al.: Compact triple-band S-shaped monopole diversity antenna for MIMO applications. ACES Journal, Vol. 28, pp. 975-980 (2015)

[20] Ojaroudi, N. and Ghadimi, N.: Design of CPW-fed slot antenna for MIMO system applications. Microw. Opt. Technol. Lett. Vol. 56, pp. 1278-1281 (2014)

[21] Al-Yasir, Y. et al.: New radiation pattern-reconfigurable 60-GHz antenna for 5G communications. Modern Printed Circuit Antennas, IntechOpen (2019)

[22] Y.Al-Yasir, et al.: A new polarization-reconfigurable antenna for 5G wireless communications. BroadNets'2018, Faro, Portugal (2018)

[23] Parchin, N. O. et al.: Frequency reconfigurable antenna array with compact end-fire radiators for 4G/5G mobile handsets. IEEE 2nd 5G World Forum (5GWF), Dresden, German (2019)

[24] Ojaroudi, N.: Design of microstrip antenna for $2.4 / 5.8 \mathrm{GHz}$ RFID applications. German Microwave Conference. GeMic 2014, RWTH Aachen University, Germany, March 10-12 (2014)

[25] Valizade, A. et al.: Band-notch slot antenna with enhanced bandwidth by using $\Omega$-shaped strips protruded inside rectangular slots for UWB applications. ACES Journal, Vol. 27, pp. 816-822 (2012)

[26] Ojaroudi, N.: Circular microstrip antenna with dual band-stop performance for ultra-wideband systems. Microw. Opt. Technol. Lett. Vol. 56, pp. 2095-2098 (2014)

[27] Kamalvand, A. et al.: Omni-directional/multi-resonance CPW-fed small slot antenna for UWB applications. ACES Journal. Vol. 28, pp. 829-835 (2013)

[28] CST Microwave Studio; ver. 2018; CST: Framingham, MA, USA (2018) 
[29] Al-Yasir, Y. et al.: A new polarization-reconfigurable antenna for 5G applications. Electronics, Vol. 7, pp. 1-11 (2018)

[30] Ojaroudiparchin, N. et al.: $8 \times 8$ planar phased array antenna with high efficiency and insensitivity properties for 5G mobile base stations. EuCAP 2016, Switzerland (2016)

[31] Ojaroudiparchin, N. et al.: Low-cost planar mm-Wave phased array antenna for use in mobile satellite (MSAT) platforms. Telecommunications Forum, Serbia, pp. 528-531 (2015)

[32] Al-Yasir, Y. et al.: New pattern reconfigurable circular disk antenna using two PIN diodes for WiMax/WiFi (IEEE 802.11a) applications. IEEE Proceeding of International Conference on Synthesis, Modeling, Analysis and Simulation Methods and Applications to Circuit Design (SMACD) 2019, Lausanne, Switzerland (2019)

[33] Parchin, N. O. et al.: Multi-band MIMO antenna design with user-impact investigation for 4G and 5G mobile terminals. Sensors. Vol. 19, pp. 1-16 (2019)

[34] Ojaroudi, N. et al.: Design of triple-band monopole antenna with meander line structure for MIMO application. Microw. Opt. Technol. Lett. Vol. 54, pp. 2168-2172 (2012)

[35] Basherlou, H. J. et al.: MIMO monopole antenna design with improved isolation for $5 \mathrm{G}$ WiFi applications. International Journal of Electrical and Electronic Science. Vol. 7, pp. 1-5 (2019)

[36] Parchin, N. O. et al.: Multi-mode smartphone antenna array for 5G massive MIMO applications. EuCAP 2020, Copenhagen, Denmark (2020)

[37] Abdollahi, M. M. et al.: Octave-band monopole antenna with a horseshoe ground plane. ACES Journal, Vol. 30, pp. 773-778 (2015)

[38] Zolghadr, J. et al.: UWB slot antenna with band-notched property with time domain modeling based on genetic algorithm optimization. ACES Journal, Vol. 31, pp. 926-932 (2016)

[39] Siahkal-Mahalle, B. H. et al.: A new design of small square monopole antenna with enhanced bandwidth by using cross-shaped slot and conductor-backed plane. Microwave Opt Technol Lett. Vol. 54, pp. 2656-2659 (2012)

[40] Mazloum, J. et al.: Compact oscillator feedback active integrated antenna by using interdigital coupling strip for WiMAX applications. ACES Journal. Vol. 28, pp. 844-850 (2013)

[41] Ojaroudi, N.: Circular microstrip antenna with dual band-stop performance for ultra-wideband systems. Microw. Opt. Technol. Lett. Vol. 56, pp. 2095-2098 (2014)

[42] Ojaroudi, N.: A novel design of microstrip antenna with reconfigurable band rejection for cognitive radio applications. Microw. Opt. Technol. Lett. Vol. 56, pp. 2998-3003 (2014)

[43] Ullah, A. et al.: Coplanar waveguide antenna with defected ground structure for 5G millimeter wave communications. IEEE MENACOMM'19, Bahrain (2019)

[44] Naser Ojaroudi Parchin and et.al., Small-Clearance Phased Array Antenna Design with Miniaturized Elements for 5G Communications, Proceedings of the 1st International MultiDisciplinary Conference Theme: Sustainable Development and Smart Planning, 28-30 June 2020, Cyberspace, pp. 139-149. 